\title{
Towards an Al-Powered Future that Works for Vocational Workers
}

\author{
Divy Thakkar \\ Google Research \\ Bangalore, India \\ dthakkar@google.com
}

\author{
Neha Kumar \\ Georgia Tech \\ Atlanta, USA \\ neha.kumar@gatech.edu
}

\author{
Nithya Sambasivan \\ Google Research \\ Seattle, USA \\ nithyasamba@google.com
}

\begin{abstract}
The future of work is speculated to undergo profound change with increased automation. Predictable jobs are projected to face high susceptibility to technological developments. Many economies in Global South are built around outsourcing and manual labour, facing a risk of job insecurity. In this paper, we examine the perceptions and practices around automated futures of work among a population that is highly vulnerable to algorithms and robots entering rule-based and manual domains: vocational technicians. We present results from participatory action research with 38 vocational technician students of low socio-economic status in Bangalore, India. Our findings show that technicians were unfamiliar with the growth of automation, but upon learning about it, articulated an emic vision for a future of work in-line with their value systems. Participants felt excluded by current technological platforms for skilling and job-seeking. We present opportunities for technology industry and policy makers to build a future of work for vulnerable communities.
\end{abstract}

\section{ACM Classification Keywords}

H.5.m. Information Interfaces and Presentation (e.g., HCI): Miscellaneous

\section{Author Keywords}

Future of work; India; Vocational technicians; AI; Automation; Policy; Algorithmic Fairness; Skills; HCI4D

\section{INTRODUCTION}

Accelerated progress in computing power and artificial intelligence (AI) raises compelling, polarising questions about the impact of automation on jobs, skills, and wages. Job losses from automation are believed to be inevitable in many technology and policy circles $[1,40,63]$. For example, in firm conviction that a jobless future is imminent, technologists such as Elon Musk and Sam Altman have publicly advocated

Permission to make digital or hard copies of part or all of this work for personal or classroom use is granted without fee provided that copies are not made or distributed for profit or commercial advantage and that copies bear this notice and the full citation on the first page. Copyrights for third-party components of this work must be honored. For all other uses, contact the owner/author(s).

CHI '20, April 25-30, 2020, Honolulu, HI, USA.

Copyright is held by the author/owner(s).

ACM ISBN 978-1-4503-6708-0/20/04.

http://dx.doi.org/10.1145/3313831.3376674 for social safety nets through Universal Basic Income (UBI) programmes [19].

Labour markets in the Global South are especially susceptible to trends in automation. Entire industries built around rule-based jobs like call centres, technology outsourcing, and low-level factory jobs could face the risk of job destabilisation from automation (e.g., [25, 29, 33, 50]). In a quantification study done by Frey and Osborne, the labour forces prone to highest risk from computerisation were those involved in routinised and manual tasks, such as production workers [29]. Despite the growing importance of implications of the Future of Work, research remains predominantly shaped on western populations (e.g., $[16,33,51])$, with limited understanding of anticipated futures in other infrastructural, social, and economic realities. Understanding perceptions of promise and risk of automation and future-readiness among rule-based workers in the Global South is crucial for designing inclusive future of work policy.

In this paper, we examine perceptions and practices around AI-powered futures among vocational technicians-a socioeconomically disadvantaged yet large community of rule-based workers in India and other emerging economies. Vocational technicians are projected to be susceptible to computerisation $[26,41]$. Vocational technicians constitute a critical labour force that transitions from high-school qualification to skilled technicians, specialising in fields like data entry operations, electrical wiring, and welding [58]. An estimated 1.5 million students are enrolled in over 15,000 vocational training institutes in India today [52]. The Indian government has made participating in vocational training a national priority, targeting the training of 500 million people by 2022 with 21 st century skills [57]. India represents a distinct backdrop where more than half the population is below twenty-five years of age and the informal sector comprises $72 \%$ of the economy, presenting a large demographic dividend that can significantly impact the country's socioeconomic development [18]. Despite the heavy investment and growth in the vocational labour force, impacts of automation may likely significantly affect these technicians, due to the predictable, repetitive, and frequently mechanistic nature of their jobs [25, 29].

We share our findings from conducting participatory action research with 38 vocational technician students of low socioeconomic status in Bangalore, India. Our research questions focused on aspirations that led participants into vocational training, their experiences with skilling and employment plat- 
forms, and their interpretations and visions of futures of work and automation. We found that vocational technicians, socially and economically disadvantaged, viewed technical expertise as a powerful vehicle to break from boundaries of caste and class. Participants perceived automation as having limited impact on future livelihoods, expressing that their hard-earned vocational expertise was irreplaceable. Contrary to the dominant discourse on the future of work (e.g., [16,37]), our participants were unfamiliar with the growing role of $\mathrm{AI}$ in rule-based tasks. Upon learning about automation, our participants then articulated an emic vision for the future of work, seeking legal protections, unionising, workplace collaboration, and accountability from employers and technology makers. However, as active users of technological platforms for skill-building and job-seeking, our participants were deeply excluded from gainful employment by the content and recommendations available to them. Online learning platforms were reported to not recognise or validate informal sector skilling. As up-skilling and re-skilling become paramount to employability, unmitigated algorithmic inequity further limits future preparedness of technicians. Based on these results, we present a manifesto for technical, policy, and ethical directions towards a globally equitable future of work.

Our research makes two main contributions. First, we present empirical results on local perceptions and practices around the future of work among a previously under-studied population of aspiring vocational technicians in India, which is likely vulnerable to automation trends. Our findings strengthen human-computer interaction (HCI) literature on the future of work by providing a participatory view on anticipated futures in the Global South. We also enrich HCI for Development (HCI4D) research by examining how technology might better serve aspiring, digital youth, poised to have significant impact on their country's socioeconomic development. Second, we present design and technical opportunities, social policy, and ethical principles for designing a globally equitable future of work, based on insights gained through our research.

\section{RELATED WORK}

We situate our study at the intersection of $\mathrm{HCI}$ and emergent debates around the future of work, perceptions of automation, and twenty-first skilling in a competitive, globalised context.

\section{Future of Work and $\mathrm{HCl}$}

In recent years, conversations about the future of work have been growing and indicate paths through which the field of HCI might engage with the changing nature of work. Prominent actors such as McKinsey, Deloitte, and the Organisation for Economic Cooperation and Development (OECD) argue that the availability of jobs [34,49] and working styles are changing [64], due to factors such as globalisation, automation, and the gig economy, where technology facilitates informal jobs and entrepreneurship [49]. Prior work in HCI on the future of work has primarily examined gig and platform workers and their motivations and practices on platforms like Amazon Mechanical Turk (AMT), TaskRabbit, and Uber, across regions, and analysed the social desirability of crowd work and how workers use these platforms for their benefit, such as $[6,22,66,73]$. Antin et al. and Ross et al. point to differences in participation on AMT between workers from the US and India, finding that workers in India have different motivations for joining the platform and may be relying on turking as a full-time job [6,66]. Hannak et al. and Zyskowski et al. also identify racial and gender bias on gig economy platforms and accessibility issues in participation [35, 84]. Themes of emotional labour and resources used by workers to improve their ratings are identified in prior work by Gloss et al. [31], Kameswaran et al. [43], and Raval and Dourish [65].

Ongoing debates on whether automation will cause deskilling (the elimination of skilled jobs), or if it can also create more new jobs remain open $[28,49]$. Further complicating this debate is the fact that talent seems to often be matched inappropriately in both the Global South and North, with employers reporting that they cannot find enough employable individuals (that is, people with STEM-related skills, competency, or work ethic), and workers feeling their skills are underutilised [49]. The future of work is also tied to the idea that technical systems are embedded in power structures [80]. For example, automation has allowed manufacturing normally outsourced to the Global South to take place at an even lower cost in the Global North, diminishing the need for low-wage workers [34]. Certain types of work, such as physical labour or predictable activities such as data entry and processing, are also more vulnerable to replacement than others [39].

Prior research in HCI does not appear to examine how workers, in their own right, in the Global South perceive their futures of work. Our research presents an empirical study on perceptions around automation by a worker community that is prone to risks of job instability and disruption. Through participatory engagement with the community, we identify a roadmap for globally equitable future of work designs and policies.

\section{Public Perceptions of Automation and AI}

Public perceptions of AI in emerging challenges such as social justice, climate change, and other threats have been studied among western audiences $[15,83]$. Cultural factors shape how $\mathrm{AI}$ is portrayed in media, culture, and everyday discussion are previously studied in context of how it influences what societies find concerning or exciting about technological developments [83]. Media discourse around perceptions of General Artificial Intelligence highlights the perceived risks of autonomy provided to such technologies $[4,30]$. Similarly, previous work has examined public perceptions of trust and safety.

Prior work by Brookings has examined the perceptions of AI through the lens of Optimism, Impact on Humanity and Jobs, and Government regulation through a quantitative examination [78]. Interestingly, while a majority of the respondents were sceptical about the impact of AI, most survey questions had over 30 per cent respondents who did not have a well formed opinion on AI. Quantitative studies focused on perceptions of job loss through automation focus on themes such as AI freeing up individuals from mundane work and show understanding among respondents about the effects of automation on blue-collar work and uncertainly of the effect on white-collar work, such as research by Smith et al. (e.g., [72]). 
Our work enriches this growing body of research on AI perceptions by expanding the focus to non-western audiences and understanding the perceptions of a population vulnerable to trends in automation.

\section{Algorithmic Fairness among Marginalized Groups}

Research on algorithmic fairness has used various lenses, critiques and observations around the role of algorithms in reinforcing or widening biases. Ajunwa et al [5] study the disparate impact in hiring of deploying AI algorithms on protected classes. Chander et al [17] argue for algorithmic design and assessment in a race and gender conscious manner instead of gender and race neutrality/blindness. Lum et al [47] find that predictive policing of drug crimes results in increasingly disproportionate policing of historically overâĂ ̌xpoliced communities. Similarly, bias in image and textual search is discussed in prior work (e.g., Otterbacher et al [60] and Buolamwini and Gebru [13]). Most relevant to us, algorithms are increasingly studied as vehicles of influence for social change on the society. Beer et al. argue that the power structures in algorithms need to be critically examined and understood given their role in everyday lives of people through social media platforms [8]. Recent work in algorithmic fairness has started to expand the conceptualization of fairness beyond economistic calculations to sociotechnical framings, notably by Selbst et al [71]-we borrow from these broader framings of fairness in systems.

Recent research has also focused on examining perceptions of fairness through participatory action research. Lee $e t$ $a l$. [46] study the need for fairness through inculcating social behaviours that cannot be expressed in mathematical terms. Woodruff et al. [81] understand the perceptions of (un)fairness among marginalised populations in the U.S., noting that while (un)fairness is experienced through vectors like racial prejudices and economic inequality, and negatively impacts user trust in systems. We extend the body of inquiry to examine the perceptions of algorithmic fairness of technical systems that potentially help uplift socio-economic opportunity for marginalised populations.

\section{Twenty-First Century Skilling}

Understanding vocational training students' work-related aspirations engages with the dominant discourse on how countries should strategise for the future of work by building up the skills and industries that will be less affected by automation [49]. Recommended strategies centre around educating a workforce that can adapt to the ways technology is changing the world, since technology might take away jobs, but could also create them, help people search for them, and leapfrog sectors of the economy [2]. As a result, educators and employers are advocating for a focus on up-skilling workers-developing both STEM skills and "creativity, critical and systems thinking, and adaptive and life-long learning" [49]. HCI research has started from the assumption that 21 st century skills are important and explored how technology can better support them, overwhelmingly among Global North populations. For e.g, Catala [14] studies systems to develop critical thinking through digital storytelling and Schrier [69] proposes augmented storytelling for 21 st century skills.
Research on skilling and employability among more diverse populations outside the realm of 21st century skills exists in HCI and ICTD, with a focus on technology for learning, job-seeking, and networking. Research has explored these behaviours among diversely underrepresented populations, such as women and individuals who are homeless (e.g., Berry et al [9] and Hendry et al [36]), visually impaired (e.g., Pal et al [62]), or of lower socioeconomic status (e.g., Dillahunt $e t$ al [21], Donner et al [24], Wyche et al [82]). A subset of this work has also designed systems that take into account the challenges that populations face in vocational training or job-seeking (e.g., $[10,12,42])$. Studies most relevant to our work include Dillahunt et al.'s study of MOOCs in the US, which highlights that MOOCs do not necessarily support the availability of social connections, mentorship, and information about new opportunities, all of which are particularly important for students from low socioeconomic strata [21]. Joshi et al. studied online tutoring platforms for students in urban India who may not be academically competitive, suggesting that platforms consider digital literacies, language and accent barriers, and the desire for skills that meet industry demands [42]. We contribute an in-depth understanding of the extent to which vocational training students use mobile phones and other devices for skilling, uncovering the challenges that arise in semi-skilled education, already immersed in a formal learning environment.

\section{VOCATIONAL TRAINING IN INDIA}

Vocational training in India is primarily provided through stateregulated Industrial Training Institutes (ITIs), which enroll 1.5 million students every year across 13,000 institutes (85\% private, $15 \%$ state-run) [23]. Students can enroll in vocational programs (typically 2-year programs) after completing tenth grade. Vocational programs span 126 trades, including engineering and non-engineering streams like plumbing, data entry, and others [58]. Vocational training offers a popular, faster alternative to high school completion, 3- or 4-year college degrees, and diploma education. Graduates are often employed as skilled labourers (in blue-collar jobs) in India's growing industrial sector [52].

With half of India's population under 25 [52], vocational training presents an entry point into the skilled labour workforce, especially for low-income communities [48]. A skilled workforce is projected to boost domestic manufacturing and availability of human resources in India, integral to the current government's 'Make in India' initiative [53,54]. The government has invested heavily in vocational training to leverage the demographic dividend towards the labour force, proposing to open 7,000 new institutes within a year [53]. Indian Prime Minister Narendra Modi is a proponent of vocational training, stating "In the last decade, we made a name for ourselves in the world through IITs. The world accepted our IITs as good institutions. But in today's world, the focus is ITI." [54].

\section{METHODOLOGY}

Our study draws from 38 semi-structured interviews conducted in Bangalore, Karnataka, from June 2018 to May 2019, with students at local vocational training institutes. The goal of our 
research was to attain a deeper understanding of the aspirations, practices, and perceptions around vocational training and the impending future of work.

\section{Participants}

The recruitment of participants took place through multiple visits to their institutes made by the first author (who is an Indian male). We used a combination of snowball and purposive sampling and stopped when our data had reached saturation saturation $[11,70]$. To obtain a balanced sample, we recruited participants across a range of engineering trades (see Table 1), across two state-run and one private vocational training institutes. Thirty-two of our participants identified as male, while six identified as female. All participants came from low socioeconomic status (SES), based on definitions per country [56], verified through income, education, and material possessions. Participants' parents worked as daily wage labourers, farmers, small business owners, and domestic help. Participants were between 18 and 24 years old. All but three participants were the first in their families to attend college. All participants were active users of Internet-enabled smart phones using at least 1.5 GB LTE per day.

We conducted interviews in person, at popular sites within and outside the institutes, such as cafeterias, lobbies, and tea stalls. We conducted these interviews in English, Hindi, and Kannada, depending on the participants' language of choice. Interview questions focused on capturing backgrounds of vocational students, motivating factors to join vocational institutes, career aspirations, skilling practices, job preparation, and views on the future of the vocational sector. We draw from the method proposed by Woodruff et al. ( [81]) to inquire on the perceptions of automation through a participatory action research. The first half of the interview was focused on current technological practices and perceptions on automation. For the second half, we introduced participants to automation trends and scenarios they were familiar with, but unrelated to participants' professions, such as Banking and Telecommunications, providing a range of positive and negative outcomes, and used participatory techniques for collaboratively working through complex ideas of impacts and visions of automation, with an open environment for sharing opinions and perceptions.

We took precautions to clearly assure participants after the first half of questions that we were moving to scenario-based questions, reminding them that they were free to not answer a question that made them uncomfortable. We paid careful attention to the responses of our participants throughout, and did not sense fears or anxieties on their part. The first author left them with their contact information, inviting them to get in touch if they had any questions or anxieties about the topics discussed. This is all in addition to following standard procedures of informed consent (in participantsâĂŹ native language) and reinforcing that participants could end the interview if desired, at any time. We thanked participants for their time, gifting them a notebook, pen, and mug.

\section{Data Analysis}

Interviews were audio-recorded (after soliciting consent) and transcribed. Participants' names were anonymised and re- placed with codes in the analysis and reporting here. We carried out a structured, qualitative data analysis to summarise and interpret the interview data. The process of analysis was iterative: we began by identifying themes at sentence-level and identified larger themes emerging from these iterations. All authors read transcripts multiple times, developed affinity clusters, and derived key themes, which we iteratively refined [76]. Emergent themes were aligned with aspirations, technology platforms, and futures as envisioned by the participants. All data were stored on a secure drive, with access to authors only. We investigate our data through a postcolonial feminist orientation as we study gender and marginality within dimensions such as caste, class, and religion.

\section{Limitations}

Our methodology utiised scenarios to paint a picture of automation in the past, present and future, and elicit reactions to potential possibilities. Scenarios may pose limited harms to participants, no more than could be engendered by reading a news article on automation (and there have been many of these in Indian media). However, we acknowledge that by participating in our study, some participants may now be confronted with the possibility and concern around AI-based technologies entering their job domains and impacting their livelihoods. Our study was qualitative in nature and may be subject to common limitations of qualitative studies, including recall bias, observer bias, participant self-censorship, and limited generalizability of the results. We aimed for a gender-balanced sample, but this was challenging because of the skewed gender ratio in non-computing trades in the institutes we visited. We also tried to gain access to more stakeholders, including parents and alumni, but this was a challenge because they were geographically dispersed. Our study took place in Bangalore, India given access to a large vocational base. However, adding sites and stakeholders in future work could help towards a more holistic understanding of vocational technicians and their technology practices.

\begin{tabular}{ccc}
\hline Area of Study & No. & Locations \\
\hline $\begin{array}{c}\text { Non-CS Trades } \\
\text { (e.g., Electrician, Fitter, Mechanist) }\end{array}$ & $26 \mathrm{~m}$ & Bangalore \\
\hline CS & $6 f, 6 \mathrm{~m}$ & Bangalore \\
\hline . Table 1: Demographics of the research study participants.
\end{tabular}

\section{FINDINGS}

We describe the aspirations of our participants in pursuing vocational programs, the digital platforms they engage with in these pursuits, and their perceptions of automated futures .

\section{The Technological Promise of Vocational Training}

Our participants pursued vocational training primarily for technological expertise, viewing vocational training as a vehicle for economic and social upward mobility. Most participants had migrated from rural areas in a quest for improved livelihoods and stable futures, particularly to move past struggles around finances, caste, domestic violence, and alcoholism among fathers. 
Breaking from Caste Discrimination through Technology

Participants recognised the importance of the core technical skills from vocational training in breaking caste barriers. Most participants came from lower caste backgrounds, whose parents and relatives were employed in lower social status professions, like daily wage labourers. Our participants reported being at the receiving end of hierarchical treatment because of their caste (which determines their social standing). Technical skills were often seen as a way to boost their challenged social standing and machines were perceived as mechanised objects, which were below the hierarchy of participants. Vocational training was also perceived as an enhancer of social capital by improving the likelihood of a desirable marital alliance.

\section{"My father is a daily wage labourer. When there is no work in the village on farms, then he comes to Bangalore and does laborious work like lifting bricks. He gets paid very less and our whole family struggles. I don't want to do that... I want a good government job so that my family doesn't have to go through trouble like this ever again, so I joined ITI."-M, 19, Fitter}

One explanation for why participants viewed technology as a vehicle to mitigate social discrimination is the growing emphasis on technology in media and government narratives [67]. Moreover, Bangalore is a well-established technology hub for multi-national and startup companies, in fields such as electrical engineering, electronics, and information and communication technologies [55]. Some participants had opted to switch from non-engineering or non-computing backgrounds to Computer Science, aspiring for upward mobility to managerial and leadership positions with technical training.

Participant's aspirations to pursue vocational education over jobs in retail or commerce stem from the perceived social standing of technical skills. A technical background is associated with employability as well as a way to earn social capital including finding better matches in arranged marriage and boosting marriage resumes.

\section{Economic Mobility through Accelerated Employability}

Vocational training was perceived by participants as a path to a "good future". Participants felt assured that such training would provide them with a job, a sentiment they reported to be echoed by their instructors, social networks, and news articles (also found in prior work $[48,59]$ ). The draw of computing for upward economic mobility in India has also been widely discussed in prior work (e.g., $[61,75])$. Participants perceived technical expertise as providing job security through managerial and leadership promotions.

\section{"I completed B.Comm. but after that I didn't know what job to get. I tried interviewing but people said I had no skills. I have come to this course to get computer skills. I will get a job at big company from here and I will grow from there to become a manager." $-F, 25, C S$}

Vocational training was seen as an accelerated path to employability. Instead of having to go through years of high school and university to find a job, participants saw vocational training as a quicker route to success, since the programs were 1-2 years long and highly application-oriented. Many participants felt that this training would not only ensure job readiness, but also help them secure $(7 x-8 x)$ higher salaries.

"I had lost all hope of working in engineering field after failing in Diploma and my father told me to do vocational training. I realised that now I can get almost same job as diploma in two years without having to do so much theory for five years."-M, 21, Machinist

As these institutes required a minimum passing score from tenth/twelfth grade exams, they seemed within reach for participants who lacked social capital, or had a modest academic performance, in contrast to college degrees.

In the next section, we describe how the agency in technical skills in vocational practice shapes how participants perceive the indispensability of their jobs over machines. .

\section{Local Visions of the Future of Work}

We describe participants' responses to questions focused on the future of work, and what they thought their own workplace futures might resemble.

\section{Perceptions of Automation}

We asked participants to reflect on the changing nature of work, given the onset of increased automation and growing popularity of the gig economy.

Our participants disassociated computers from manufacturing and production jobs. Participants did not ascribe intelligence or cognitive ability with machines, using terms like 'control', 'operate', and 'use' in the context of machines. Participants had 'object-oriented' relationships with machines and did not view them as collaborators, co-workers, or supervisors. Rather, machines and computing were viewed as efficiency tools that were controlled by operators. Participants perceived that technically complex tasks could only be performed by humans, not automation.

Participants articulated the role of technicians as executors of perfection; performing polished, complex technical tasks. According to them, technicians brought leadership and creativity skills in addition to technical skills. Importantly, technicians were seen as having expertise and skill in correcting errors (in case of change in business or technical requirements on the job), whereas machines were seen as executors of repetitive tasks with no scope for correction without human input.

"If something goes wrong at work, my colleague will teach me how to do it. So will I for him. We learn from each other-how will we learn from a machine if it does my job?"-M, 21, Electrician

We found that participants' beliefs in their skills over machines were also rooted in their sociocultural contexts. In a hierarchical caste structure where our participants have been at the receiving end of social discrimination, machines were viewed as having lower intellectual and social standing, beneath humans. In a socio-cultural context where technical careers were linked with prestige and respectable social status, participants harboured a belief that their hard-earned technical skills could not be automated. Our participants initially viewed automation optimistically; increased computerisation led to increased 
efficiency, according to them. Participants did not envision the workplace undergoing any dramatic change in the future.

"How will machine do the work? With our hands only we have to do it." $-M, 18$, Welder

In order to elicit reactions to increased computerisation, participants were introduced to past, present, and future trends in automation and professional domains where jobs were transformed. All participants were confident that their jobs were not under threat. While they understood what automation entailed, participants felt that the hard skills they had acquired could not be replicated by a machine.

"Even if robot can do some job-it cannot do what I do so well, we also have to make sure it doesn't do anything bad"-F, 21, Computer Science

\section{Workplace Relationships and Bargaining}

Participants viewed work as a central component of their identity and social standing (we noted earlier how technical skills augment social standing). We observed a deep sense of belonging to the workplace which arose from various factors. First, participants had a loyal and negotiable relationship with their employers. We observed a willingness to go above and beyond requirements for the employer, and an association of personal growth with the employer's growth. Participants discussed the importance of interpersonal relationships and social currency with their coworkers and managers, especially salient in times of need like the death of a family member, personal accidents, or marriage ceremonies, which may require extra leave or an advance salary.

"I would not ask for overtime generally because my boss will tell me to do extra only if it is really needed. If I work extra now, they will also help me when I need to take an off or need some money if something happens to me or my family members."-M, 20, Mechanic

Coworkers were perceived as integral support systems and family away from home, since most participants migrated to urban areas in pursuit of better education and job opportunities. In general, participants envisioned an ideal workplace as one where they had a sense of belonging, good peer and mentorship networks, career growth opportunities, and adequate salaries.

"Me and my colleagues eat lunch together and hang out after work. We talk about our problems and help each other."-M, 24, Fitter

\section{Outlining a Future of Work that Works}

Participants were requested to describe a future of work, in line with their values, anxieties, and aspirations. Legal protections and measures were noted to be salient in an automationenabled future. Union bodies were considered crucial for collective negotiation to protect worker rights, or for enforcement of laws such as a mandatory ratio of machines to people in a workplace. Participants noted the need for longer notice periods in case of job displacement and need for up-skilling. Costs of re-skilling and up-skilling were considered appropriate for employers to bear. Several participants mentioned the need to demand accountability of upper management for any decisions on job lay offs. In a hierarchical societal context of
India, access to upper management is often limited to lowerlevel technician workers, potentially making contestability and recourse problematic for workers.

"I should have the freedom to go to the upper management if things go wrong because of machines. Unions can also help negotiate on our behalf."-M, 21, Electrician

When asked to envision a future decision-making scenario of resource allocation in a time of decreased costs of automation vis-a-vis human labour, participants made trade-offs between revenue and goodwill of companies. Participants demonstrated empathy for workers, strongly preferring to not let go of employees. While participants perceived the cost-benefit analysis and increased throughput from computerised substitutions to be beneficial, they desired that displaced workers be employed as machine operators (due to the disassociation of intelligence with machines). Participants also sought alternate paths for displaced employees in the same company and noted the needed for re-skilling to train them for new jobs.

Participants expressed strong resistance to the concept of Universal Basic Income (UBI). As work was viewed as an integral part of their identities as well as a place for social interactions, participants viewed a life without work and free income as "going wrong", "going mad", and "wasting their life".

"I need to work-any form of work. If I do not and sit at my home even if I get free money, I will go mad if I do not do work and meet my colleagues."-M, 22, Mechanic

On the topic of freelancing and the gig economy, participants were open, even enthusiastic, towards the possibility of pursuing gig work outside of their full-time job's working hours. However, participants viewed gig work as being complimentary to full-time jobs, but not a sole profession. In a societal context where stable jobs in industry or a manufacturing plant are coveted, freelancing, on-demand, and contract work was viewed as highly undesirable. Participants also noted their lack of awareness regarding avenues where they could find such work.

\section{Algorithmic Fairness in Education, Skilling, and Jobs}

We now turn to results on present day usage of skilling and job search platforms by our participants, to understand how current experiences with online platforms and tools may enable preparedness for future skills. Participants frequently turned to online platforms for learning, complementing classroom training and enhancing practical skills. As active users of the Internet, all participants owned smartphones and routinely queried search engines, video repositories, and social networking sites to advance their careers. Below we discuss this use of online platforms in depth, while also detailing the challenges participants faced in the process.

\section{Limited Discoverability of Contextually-Relevant Content}

Participants discussed turning to the Internet for various learning intents, such as interview preparation, visualising jobs through videos, augmenting classroom learning and job readiness, project-based learning, learning English, and discovering past exam questions. Participants reported that that some of 
these information needs were better addressed than others via the online platforms they accessed.

Participants reported watching videos on specific topics to augment ideas or abilities that they were unable to fully grasp through their lectures at school, such as welding, fitting, and grinding. All of them turned to videos for additional contextualised explanations of concepts. Participants from computingrelated courses, in particular, relied on online searches for code snippets as well.

"I search for videos for making projects. I generally know components well enough from class tutorials before I start watching a project video, but I learn how to work on real machines from videos, especially when we are given a project in class like repair a fridge or make a new part."-M, 19, Electrician

Although participants voiced a clear need for accessing content related to practical learning, they also frequently encountered challenges with the content served to them. One key challenge was that of language; participants were taught in Kannada and familiar with vernacular terms, but the content online was typically in English (or formal, unrelatable Kannada). Even when participants knew English, they struggled with instructional videos on account of cultural disconnects, such as the accents of instructors or their style of content delivery. They were unsuccessful in identifying videos featuring instructors that they could relate to.

"They (non-Indian lecturers) talk so fast fast, I get confused and stop the video and ask my friend and teacher. Teacher in college is teaching in Kannada, but Internet is not teaching in Kannada."-M, 19, Mechanic

Additionally, search terms - even if they were in Englishoften carried a different meaning online versus in participants' contexts. For example, participants reported using terms such as "welding job" or "grinding job" where "job" referred to an activity or a task as commonly used in the classroom, rather than an employment opportunity. They reported being unable to find relevant content by adding such keywords to their queries. We also learned that searching for learning videos by profession, such as "grinder" or "fitter", led to a host of irrelevant results. Terms that were commonly used in some professions such as "weight machine" also led to semantically mismatched results like exercise videos.

"If I look for 'grinding machine how to use' videos, first I will see video of mixer-grinder (blender) which is used in the kitchen and not related to my syllabus."

-M, 20, Grinder

Many participants reported browsing videos by inserting keywords from their textbooks to find the most relevant learning content. Some reported challenges in gauging what type of and order of videos was best-suited for their learning; for example, in related videos.

"I see a video but I don't know what to see after that. So I see my textbook and search for the next video accordingly." $-F, 22, C S$

\section{Semi-Skilled Learning is Difficult on MOOCs}

Participants reported receiving paper certificates at the culmination of each term to indicate the skills that had been acquired therein. These were vital to our participants in their job searches; a dossier of these would be carried to job interviews as proofs of various milestones in their academic training. These acted as a sign of continuity and stamps of government approval towards participants' learning, serving as a differentiating factor in interviews. All participants considered them important for securing a good job, sharing that they inspired confidence among interviewers. They also viewed these indicators of government credibility as badges of honour to show their immediate and extended families.

"We get certificate after ITI and if we do apprenticeship, we get another certificate and lot of skills. If no certificate, then no job, and no life for us."-M, 19, Fitter

Participants reported that certificates were a key component of their interviews, and needed to be available in physical form (and preferably laminated). Physicality of certificates added another layer of credibility.

Most participants were unaware of online certification or MOOCs. After we explained the intent and operations of online certification to gauge the interest of participants, many showed interest in learning how these could improve their employment prospects. However, currently MOOCs only cater to college education or K-12 learning, and there are no platforms that cater to vocational training students that would provide validation of their learning.

"I watch a lot of online videos for doing well in coursework but there is no way to show in job interview on what I learnt."-M, 18, Instrumentation

Participants were interested in the prospect of attaining certificates from government organisations for non-CS trades and private technology companies for CS trade participants. All reported an interest in seeking certifications from foreign universities. However, they had concerns around the worth and credibility of digital certificates, and expressed a preference for online certification that could translate to physical certificates.

The three participants who knew about online certificates previously mentioned that instances of fraud experienced by relatives had made these participants more cautious.

"I get ads about online degree sometimes but I think it is all fake... I would like to see names of big big universities or government organisations in degree then I can think that it is good."-M, 18, Grinder

Building a professional profile and learning to interview were key to securing a job, participants recognized. Although there is much learning content online on related topics, this requires job-seekers to have access to privileged social networks that they lack (also noted in prior work [20]. In the absence of this knowledge, participants struggled with building their resumes, which impacted their ability to create professional profiles. Some participants mentioned the use of cybercafes to professionalise their profiles (more on this below). 


\section{Job Platforms Exclude Vocational Skills}

Participants mentioned the various avenues they used for job searches, including internal social networks, online search, and institute placements. Government jobs were seen as being more reliable, stable, lucrative, and prestigious. However, they were limited in number, and required job-seekers to complete an additional round of competitive examinations. Those in the CS trade were more keen on private jobs and frequently turned to various online avenues in their search. Participants used portals such as Naukri and Govtjobsportal [3], in addition to directly searching for jobs on Google Search. To stay updated on openings in government organisations, they frequently subscribed to push notifications on relevant applications, and checked for updates through Google Search.

"I have a lot of apps installed on my phone to stay upto-date so that I don't miss any deadline for government job...I download app most of the times whenever I find app so I don't miss any updates and get a notification on my phone."-M, 18, Mechanic

We observed high reliance on personal social networks for finding government jobs among non-CS participants. Many participants spoke about drawing on their familial relations for help with finding a job.

"My uncle works in HAL (Hindustan Aeronautics Limited), he will find a job for me in HAL. He told me to complete ITI and he will look for me so I am not as worried about finding a job."-M, 20, Fitter

Participants reported using WhatsApp groups for dissemination of information regarding upcoming institute placements and other job openings discovered on the Internet. Participants emphasised that they would apply to whatever job openings they had seen on WhatsApp since these came from their social linkages - a trusted source, especially given that there were fake jobs aplenty, as discussed below.

"My friend is sending me a job on social media, how can it be fake? On Internet, I cannot be sure which one is fake. Many people on the Internet are asking for money before interview is what I have heard." $-F, 21, C S$

\section{Mismatched Employment Opportunities}

Many participants reported not finding relevant jobs for their skill-set online, and that the job postings they came across catered primarily to students with college degrees. We found that online portals allowed filtering by skills and by profession. Our participants frequently looked for jobs that matched their skills/profession such as "grinder" or "grinding" on these filters and ended up not finding relevant skill-sets on the lists of postings. Participants also reported difficulties in finding region-specific jobs through these portals.

"I try searching for jobs in Bangalore but I keep getting jobs in North India. I try very hard to find jobs here because I can't leave family in Bangalore."-M, 22, Welder

Participants detailed instances where portals asked for a number of details that did not apply to them, such as high school and college grades, which confused them and resulted in "incomplete profiles", leading to a common perception that these portals do not cater to vocational training students. Nevertheless, the popularity of these portals, along with the hope of finding a job, kept participants engaged on these platforms.

"There are so many jobs online, but I do not find anything for my skills. I don't even know the meaning of some jobs I am shown, but for ITI I do not know the easiest way to find jobs so I type on Google and try to find something."M, 20, Mechanic

\section{Navigating Fraudulence}

Several participants spoke about the fear of being scammed during the online job search process, sharing second-hand stories of companies asking for money to conduct interviews for candidates. Some participants recalled stories of going to far-off interview locations only to realise upon arrival that there was no company or interview to attend. Such stories experienced by close relatives or friends negatively impacted how participants perceived online job postings. Participants also reported not being able to distinguish between genuine and fake postings. They generally trusted the first few results on search portals for non-employment related searches, but would scroll through several pages on job portals to find and apply for jobs.

Some participants paid a large fee to cybercafe owners to apply for jobs, because of perceived limitations in submitting a professional job application. The local businesses charged a fixed amount as a processing fee (USD 3-6) per job application and an application fee for each job (ranging from USD 3-5), said to be payable to the company or hiring organisation (likely an inaccurate claim).

\section{TOWARDS AN EQUITABLE FUTURE OF WORK}

Our findings show that vocational technicians perceive their futures to be unperturbed by automation, expressing great optimism over their human technical expertise. After learning about the growing power of automation, our participants outlined their visions of a future of work. As socio-economically disadvantaged workers, technicians reported being discriminated by current platforms for skilling and job-seeking-a bias gap that could worsen with time, if unchecked. Key questions that we might ask within the HCI community are how do we ensure that the future of work is less socially inequitable? How do we challenge our ways of thinking about algorithmic fairness? How do we design for fostering aspirations through skilling and employment? We now discuss open questions and design insights for the HCI community towards equipping vocational technicians to meaningfully enter and sustain in the workforce, with our insights from India. We recommend specific areas for designers, policy makers and technology companies to consider while developing technologies and policies that affect the state of work globally.

\section{Recognise the Structural Importance of Work}

The economic mobility of an individual is heavily shaped by a stratified societal structure, limiting what they might realistically aspire towards, as prior literature on the Indian caste system has documented [38]. The rising complexity of machines threatens to reverse the perception that machines occupy a position lower than that of those from lower castes, 
impacting the social standing of the latter. It is crucial for technologists and policy makers to ensure that generations of social capital accrued by those from lower castes in securing socially respected jobs is not impacted by automation. Social mobility also depends upon how one's employment is perceived by others. We found that technical skills and degrees were proudly displayed on marriage resumes and carried social prestige. How might automation impact social reputation? UBI was not considered an adequate compensation in this regard, facing strong opposition and potential stigma in receiving free income with no work. Automation could be positively employed to reverse age-old discrimination of caste and class. As lower caste members are often relegated to technician jobs and operator roles, machines can not only enable higher social status by virtue of their growing intelligence and complexity, but could potentially free up technicians to up-skill themselves (provided adequate social policy programs for upskilling exist). Our findings also point to the importance of recognising workplace relationships and social currency in any future of work policy, and the implications of replacing symbiotic human-human relations with automation.

\section{Architect Policy and Protections for Semi-Skilled Workers} Our findings point to the importance of establishing labour unions for company and factory workers, in order to collectively demand for adequate pay, benefits, and working conditions in automation settings. Participants discussed the need for transparency and accountability while anticipating decisions concerning replacement of labour with automation. Comprehending and having the capacity for recourse, including legal and political options, with any high-level automation decisions is important for worker rights and morale. Our participants were further marginalised by limited English fluency, lower castes, and limited technological awareness. Our participants sought out holistic education to place them at par with elite counterparts, through various technology platforms and social networks, contrary to the low level skills training provided by the government. Similar to research by Sarkar on low income youth in Delhi, vocational workers seek up-levelling of other privileges beyond technical skills, such as English competency, workplace professionalism, and social privileges [68]. Such holistic aspirations need to be recognised in any solution, and high-quality education in local languages should be mandated to be provided for free by governments and companies to workers. India and other emerging economies represent large markets for low-cost crowdwork, including automationbased trends like image labelling and inference testing (refer to heteromation [27] and fauxtomation [74] for more on human labour in automation). However, it is important for solutions to go beyond low-skill technology work to holistic empowerment in the Global South. A broader architecture of employer accountability, safety nets, and worker rights is important to inclusively shaping the future of work.

\section{Build an Understanding of Automation among Workers}

Communities vulnerable to computerisation may require a better understanding of automation to help distinguish hype and panic from factual data. In our study, vocational technicians had folk models around automation and computerisation as 'machine-like' production, not artificial intelligence, such as machine learning or robots. As a result, they did not initially foresee any significant impacts of automation on their livelihoods or work practices in the future. Compare with widespread concern on robots and computers replacing human jobs by $72 \%$ of Americans in a 2017 Pew survey [16] — neither unfounded panic nor lack of awareness is favourable to worker preparedness or morale. Our participants made use of AIbased applications like social media, video platforms, and search engines in daily life (albeit unfamiliar with the underlying technology). Creating a public understanding of AI with actual breakthroughs and implications can help generate informed views on automation, avoiding speculation. Technology companies could develop literacy by publishing case studies in vernacular languages and local context around the use of AI technologies relevant to vocational technicians and others at risk. Public understanding of AI could help empower workers and gradually

\section{Address Gender Proactively in the Future Workforce}

Designing an equitable future of work must also consider gendered implications of automation on the workforce. In India, where the percentage of women in the workforce is already a low $22 \%$ [7], automation may impact jobs around content moderation, data entry, call centres, which employ a large number of women. The skewed gender balance in our study, except in the area of computing, raises questions around gendered associations with certain genres of work. For example, care work-typically seen as a feminine, pink-collar undertaking - is predicted to grow in importance in spite of automation [49]. Job displacements may disproportionately impact women, in career growth, social and political status, and unemployment among women. Future work focusing on a broadened understanding of gender and automation will be imperative to gender equity.

\section{Expand Vernacular Content and Datasets}

We found that participants frequently felt under-recognised as they searched using localised queries such as "grinding" and "fitting". We highlight the need for combating algorithmic bias and generating richer, more inclusive machine learning datasets that are representative of diverse occupations (beyond white-collar jobs) and learning methodologies (such as practical hands-on processes). Participants' lack of confidence in technology assisting them in securing livelihoods was evident; building this confidence will be an essential step towards supporting re-skilling and up-skilling if and when jobs are replaced due to automation and there is increasing dependence on online platforms to provide pathways to employment.

We learned that online resources were not equipped to support participants' employment-related challenges. Enhanced search literacy to iterate on searches or find alternative queries was limited because of their post-secondary education and limited English knowledge. Instructional and applied videos by western presenters were reported to be difficult to understand due to accent and context differences. Participants reported difficulty with finding continuous instructional content to enhance their skills, relying instead on suggestions and thumbnails. Moreover, there were no digital content aggregators for vocational content at the state or national level. 
We find that search filters in employment websites were reported to not include options for technician roles, for example, jobs were reported to be searchable for civil engineering, but not for plumbers and mechanists. Algorithmic notions of a 'complete profile' or an 'ideal profile' towards white-collar professions may further distance technicians from finding gainful employment, even with updated skills.

\section{Recognise Technician Jobs in Employment Solutions}

Technology design can play a role in how aspirations are shaped, supported, and cultivated over time [45,77]. Recommendation systems can also be designed to surface content that creates learning trajectories for vocational technicians; this could address the problem of not having a clear learning path for cultivating and fulfilling aspirations. Internal social networks have been found to be important for job searches and choosing career paths $[20,44,79]$. Our participants noted the importance of identifying community role models, especially while choosing new career paths. Highlighting relatable role models who have pursued new paths, whether in upskilling or deman accountability, can be relevant [75].

Many participants reported that preparing to be a professional was challenging, with no starting point online; instead they turned to known entities such as cybercafes for help. Participants reported paying USD \$3-6 (a substantial amount) to cybercafe staff to create CVs and fill out online profiles because of their perceived lack of digital literacy skills. Designers may consider surfacing sample vocational CVs and creating easy-to-use CV builder tools that cater to technicians. Digital literacy workshops could introduce vocational technicians to the array of professional resources on the web, such as interview preparation tips, salary negotiation, and CV-building.

Institute-sponsored campus placements and job fairs were present, but participants relied on finding jobs through social media and employment websites. However, vocational jobs were reported to be non-existent on popular employment websites. Participants relied on the closed web of social media, moving away from the open web of platforms and websites. As a result, discovery of new job opportunities was limited. Fake job opportunities were commonly reported, without discerning mechanisms to determine authenticity.

Employment platforms can be more mindful of technician jobs, who are crucial counterparts to engineering and scientific jobs. Creating fields and affordances within profiles (e.g., indicating specialisation areas and enlisting technical skills) and search filters (e.g., searching by vocational trade), and correspondingly getting more state and private players to enlist their job availability online could lead to enhanced prospects for vocational jobs. Similarly, a critical examination of how profiles are evaluated across different job categories will be a step in the right direction to avoid algorithmic bias. At the same time, verifying authenticity of jobs could protect technicians from financial and emotional damage.

\section{Foster and Address Blue-Collar Worker Aspirations}

Skilling is a recurring theme in our study and we find that participants work around with systems that do not serve them well by finding arrangements to combine their offline social networks with social media, video, and search platforms to meet their skilling and job search needs. Participants especially noted the need to skill online when jobs are at risk owing to their economic constraints of not being able to go back to school again at a later stage.

Participants had little awareness of MOOCs and formal learning platforms, resorting instead to informal learning platforms like video apps. MOOCs do cater towards high-skill and lucrative technical skills, rather than more basic forms of technical training. For example, while there are several basic courses on data science and Python programming (that require prerequisite coding and analytical skills), professional data entry finds little representation on conventional MOOCs. Participants appreciated the idea of getting certifications from reputed national and international universities, but popular education platforms do not offer vocational courses at present. Public and private institutions may consider partnering with MOOCs platforms to provide content and scale their teaching. Physical certificates should also be considered by MOOC designers.

Boosting local user-generated vocational content through partnerships and initiatives may present more locally appealing and pertinent media. Perhaps search literacy should be built into curricula [32], due to the increasing focus on 21st century skills. By designing equitable and fair access to knowledge and opportunity platforms, more informal sector workers can access skills and employment, regardless of power, knowledge and privilege. As some future of work theorists argue, the employment relevance question is about skill reinvention rather than fully displacing jobs $[49,51]$. Enabling recognition of vocational trades in skilling and employment platforms could enable technicians to upgrade to 21 st century skills.

\section{CONCLUSION}

We presented our findings from participatory action research conducted with 38 vocational technicians in Bangalore, India, where we examined the perceptions and practices of vocational technicians who are projected to be risk in an AI-powered future. We described the aspirations of a socio-economically disadvantaged population who view gaining technical skills as a way to break the boundaries of caste and class. We analysed the perceptions of automation among vocational technicians, and outlined a ground-up vision for a future of work as described by our participants. We found that skilling and employment platforms display algorithmic bias against our participants who rely on these systems as a way to up-skill and re-skill in an AI-powered future. Based on our results, we identified implications for design, social policy, and ethical principles for an equitable future of work that meaningfully advances technicians.

\section{ACKNOWLEDGEMENTS}

We wish to thank our research participants, Ashwani Sharma, Jess Holbrook, Daniel Russell, Maggie Johnson, Jose Faleiro, Tulsee Doshi, Ben Hutchinson, Michael Falgoust, Alex Beutel, and David Nemer. We especially thank Naveena Karusala for her contributions.

\section{REFERENCES}

[1] 2017. Harnessing automation for a future that works I McKinsey \& Company. https://www.mckinsey.com/featured- 
insights/digital-disruption/harnessing-automationfor-a-future-that-works. (January 2017). (Accessed on 08/18/2018).

[2] 2017. What technology can do for Africa. https://www.economist.com/special-report/2017/11/09/ what-technology-can-do-for-africa. (November 2017).

[3] 2019. govtjobsportal. http://www.govtjobsportal.in. (August 2019).

[4] 2019. Understanding the public perception of AI. https://medium.com/goodai-news/understanding-thepublic-perception-of-ai-a14b0e6b6154. (February 2019).

[5] Ifeoma Ajunwa, Sorelle Friedler, Carlos E Scheidegger, and Suresh Venkatasubramanian. 2016. Hiring by algorithm: predicting and preventing disparate impact. Available at SSRN (2016).

[6] Judd Antin and Aaron Shaw. 2012. Social desirability bias and self-reports of motivation: a study of amazon mechanical turk in the US and India. In Proceedings of the SIGCHI Conference on Human Factors in Computing Systems. ACM, 2925-2934.

[7] The World Bank. April 2019. Labor force participation rate, female.

https://data.worldbank.org/indicator/SL.TLF.CACT.FE.ZS. (April 2019).

[8] David Beer. 2009. Power through the algorithm? Participatory web cultures and the technological unconscious. New Media \& Society 11, 6 (2009), 985-1002.

[9] Taylor Averill Berry. 2012. The Use of Mobile Phones to Address an Unemployment Crisis: an Examination of South Africa. (2012).

[10] B Bhavani, Srividya Sheshadri, and R Unnikrishnan. 2010. Vocational education technology: rural India. In Proceedings of the 1st Amrita ACM-W Celebration on Women in Computing in India. ACM, 21.

[11] Patrick Biernacki and Dan Waldorf. 1981. Snowball sampling: Problems and techniques of chain referral sampling. Sociological methods \& research 10, 2 (1981), 141-163.

[12] Lal Bozgeyikli, Evren Bozgeyikli, Andrew Raij, Redwan Alqasemi, Srinivas Katkoori, and Rajiv Dubey. 2017. Vocational rehabilitation of individuals with autism spectrum disorder with virtual reality. ACM Transactions on Accessible Computing (TACCESS) 10, 2 (2017), 5.

[13] Joy Buolamwini and Timnit Gebru. 2018. Gender shades: Intersectional accuracy disparities in commercial gender classification. In Conference on fairness, accountability and transparency. 77-91.

[14] Alejandro Catala, Mariët Theune, Hannie Gijlers, and Dirk Heylen. 2017. Storytelling as a Creative Activity in the Classroom. In Proceedings of the 2017 ACM SIGCHI Conference on Creativity and Cognition. ACM, 237-242.

[15] Stephen Cave, Claire Craig, Kanta Sarasvati Dihal, Sarah Dillon, Jessica Montgomery, Beth Singler, and Lindsay Taylor. 2018. Portrayals and perceptions of AI and why they matter. (2018).

[16] Pew Research Center. 2017. Automation in everyday life. Pew (2017).

[17] Anupam Chander. 2016. The racist algorithm. Mich. L. Rev. 115 (2016), 1023.

[18] C.P. Chandrashekhar. 2014. IndiaâĂŹs informal economy. https:

//www.thehindu.com/opinion/columns/Chandrasekhar/ indias-informal-economy/article11119085.ece. (September 2014).

[19] Weller Chris. June 2017. Business Insider. https://www.businessinsider.com/sam-altman-missionfix-american-democracy-2017-6. (June 2017).
[20] Tawanna R Dillahunt, Jason Lam, Alex Lu, and Earnest Wheeler. 2018. Designing Future Employment Applications for Underserved Job Seekers: A Speed Dating Study. In Proceedings of the 2018 Designing Interactive Systems Conference. ACM, 33-44.

[21] Tawanna R Dillahunt, Sandy Ng, Michelle Fiesta, and Zengguang Wang. 2016. Do massive open online course platforms support employability?. In Proceedings of the 19th ACM Conference on Computer-Supported Cooperative Work \& Social Computing. ACM, 233-244.

[22] Tawanna R Dillahunt, Xinyi Wang, Earnest Wheeler, Hao Fei Cheng, Brent J Hecht, and Haiyi Zhu. 2017. The Sharing Economy in Computing: A Systematic Literature Review. PACMHCI 1, CSCW (2017), 38-1.

[23] Ministry of skill development Directorate General of Training (DGT). 2015. Brief note about Industrial Training Institutes.

http://dget.nic.in/content/institute/keystatistics.php. (January 2015).

[24] Jonathan Donner, Shikoh Gitau, and Gary Marsden. 2011. Exploring mobile-only Internet use: Results of a training study in urban South Africa. International Journal of Communication 5 (2011), 24.

[25] The Economist. 2018. A study finds nearly half of jobs are vulnerable to automation. https://www.economist.com/ graphic-detail/2018/04/24/a-study-finds-nearly-halfof-jobs-are-vulnerable-to-automation. (April 2018).

[26] Werner Eichhorst, Núria Rodríguez-Planas, Ricarda Schmidl, and Klaus Zimmermann. 2012. A roadmap to vocational education and training systems around the world. (2012).

[27] Hamid Ekbia and Bonnie Nardi. 2014. Heteromation and its (dis) contents: The invisible division of labor between humans and machines. First Monday 19, 6 (2014).

[28] Wolfgang Fengler. 2017. Future Development Reads: The ongoing debate about the future of work. https://www.brookings.edu/blog/future-development/ 2017/12/08/future-development-reads-the-ongoingdebate-about-the-future-of-work/. (December 2017).

[29] Carl Benedikt Frey and Michael A Osborne. 2017. The future of employment: How susceptible are jobs to computerisation? Technological forecasting and social change 114 (2017), 254-280.

[30] Tad Friend. 2018. How frightened should we be of AI. https://www.newyorker.com/magazine/2018/05/14/howfrightened-should-we-be-of-ai. (May 2018).

[31] Mareike Glöss, Moira McGregor, and Barry Brown. 2016. Designing for labour: uber and the on-demand mobile workforce. In Proceedings of the 2016 CHI conference on human factors in computing systems. ACM, 1632-1643.

[32] Google. 2019. Google Search Education. https:// www.google.com/insidesearch/searcheducation/index.html. (August 2019).

[33] Maarten Goos and Alan Manning. 2007. Lousy and lovely jobs: The rising polarization of work in Britain. The review of economics and statistics 89, 1 (2007), 118-133.

[34] The World Bank Group. 2017. Trouble in the Making? The Future of Manufacturing-Led Development. http://www.worldbank.org/en/topic/competitiveness/ publication/trouble-in-the-making-the-future-ofmanufacturing-led-development. (September 2017).

[35] Anikó Hannák, Claudia Wagner, David Garcia, Alan Mislove, Markus Strohmaier, and Christo Wilson. 2017. Bias in Online Freelance Marketplaces: Evidence from TaskRabbit and Fiverr.. In CSCW. 1914-1933. 
[36] David G Hendry, Jill Palzkill Woelfer, and Thuy Duong. 2017. U-District Job Co-op: constructing a future vision for homeless young people and employment. Information Technology \& People 30, 3 (2017), 602-628.

[37] Hiringlab.org. 2019. WhoâĂŹs Afraid of Automation? https://www.hiringlab.org/2019/01/10/automation-aifears-jobs/. (January 2019).

[38] Viktoria Hnatkovska, Amartya Lahiri, and Sourabh B Paul. 2013. Breaking the caste barrier intergenerational mobility in india. Journal of Human Resources 48, 2 (2013), 435-473.

[39] McKinsey Global Institute. 2018. How will automation affect jobs, skills, and wages? https://www.mckinsey.com/featuredinsights/future-of-organizations-and-work/how-willautomation-affect-jobs-skills-and-wages. (March 2018).

[40] Manyika James. 2017. Technology, jobs, and the future of work I McKinsey \& Company. https://www.mckinsey.com/featured-insights/employmentand-growth/technology-jobs-and-the-future-of-work. (May 2017).

[41] Richard K Johanson and Arvil V Adams. 2004. Skills development in sub-Saharan Africa. The World Bank.

[42] Meghna Joshi, Tanmay Joshi, and Nimmi Rangaswamy. 2018. Scaling Classroom IT Skill Tutoring: A Case Study from India. In Proceedings of the 2018 CHI Conference on Human Factors in Computing Systems. ACM, 630.

[43] Vaishnav Kameswaran, Lindsey Cameron, and Tawanna R Dillahunt. 2018. Support for social and cultural capital development in real-time ridesharing services. In Proceedings of the 2018 CHI Conference on Human Factors in Computing Systems. ACM, 342.

[44] Neha Kumar. 2014. Facebook for self-empowerment? A study of Facebook adoption in urban India. New media \& society 16, 7 (2014), 1122-1137.

[45] Neha Kumar, Marisol Wong-Villacres, Naveena Karusala, Aditya Vishwanath, Arkadeep Kumar, and Azra Ismail. 2019. Aspirations-based design. In Proceedings of the Tenth International Conference on Information and Communication Technologies and Development. ACM, 2.

[46] Min Kyung Lee and Su Baykal. 2017. Algorithmic mediation in group decisions: Fairness perceptions of algorithmically mediated vs. discussion-based social division. In Proceedings of the 2017 ACM Conference on Computer Supported Cooperative Work and Social Computing. ACM, 1035-1048.

[47] Kristian Lum and William Isaac. 2016. To predict and serve? Significance 13, 5 (2016), 14-19.

[48] R Maithreyi, Shruti Padmanabhan, Niveditha Menon, and Jyotsna Jha. Skills Development, Social Mobility and Educational Change: A Sociological Analysis of the Effects of the National Policy on Skills Development in India. (????).

[49] James Manyika. 2017. What technology can do for Africa. https://www.mckinsey.com/featured-insights/employmentand-growth/technology-jobs-and-the-future-of-work. (November 2017).

[50] James Manyika, Susan Lund, Michael Chui, Jacques Bughin, Woetzel Jonathan, Parul Batra, Ryan Ko, and Saurabh Sanghvi. 2017. Jobs lost, jobs gained: What the future of work will mean for jobs, skills, and wages. http://www.worldbank.org/ en/topic/competitiveness/publication/trouble-in-themaking-the-future-of-manufacturing-led-development. (September 2017).

[51] James Manyika and Kevin Sneader. 2018. AI, automation, and the future of work: Ten things to solve for.

https://www.mckinsey.com/featured-insights/future-oforganizations-and-work/ai-automation-and-the-futureof-work-ten-things-to-solve-for. (June 2018).
[52] Department of School Education Ministry of Human Resource Development and Literacy. 2016. Educational Statistics at a glance. http://mhrd.gov.in/sites/ upload_files/mhrd/files/statistics/ESG2016_0.pdf. (February 2016).

[53] Mint. 2016. 'We Can Be World's Human Resource Capital', Says PM Modi at 'Skill India' Launch. https://www.livemint.com/Politics/ hQAbVWs5iiXe21VhCAHWNN/PMO-directs-skills-ministryto-open-7000-ITIs-within-a-year.html. (January 2016).

[54] NDTV. 2015. 'We Can Be World's Human Resource Capital', Says PM Modi at 'Skill India' Launch. https://www.ndtv.com/ cheat-sheet/we-can-be-worlds-human-resource-capitalsays-pm-modi-at-skill-india-launch-781792. (July 2015).

[55] MSME-Development Institute Government of India. 2016. Brief note about Industrial Training Institutes. http://dcmsme.gov.in/dips/state_wise_dips/ state_profile_karnatka_11316.pdf. (January 2016).

[56] Market Research Society of India. 2011. The New SEC system. http://mruc.net/uploads/posts/ b17695616c422ec8d9dadafc1c3eec26.pdf. (May 2011).

[57] Times of India. August 2018. Govt sets target to skill 500 million people by 2022 .

https://timesofindia.indiatimes.com/home/education/ news/Govt-sets-target-to-skill-500-million-peopleby-2022/articleshow/11420731.cms. (August 2018).

[58] Directorate General of Trade. 2017. Trade Syllabus. http: //dget.nic.in/content/innerpage/trade-syllabus.php. (May 2017).

[59] Aya Okada. 2012. Skills development for youth in India: Challenges and opportunities. Journal of International Cooperation in Education 15, 2 (2012), 169-193.

[60] Jahna Otterbacher, Jo Bates, and Paul Clough. 2017. Competent men and warm women: Gender stereotypes and backlash in image search results. In Proceedings of the 2017 CHI Conference on Human Factors in Computing Systems. ACM, 6620-6631.

[61] Joyojeet Pal. 2008. Computers and the promise of development: aspiration, neoliberalism and âĂđtechnolityâĂ§ in IndiaâĂ§s ICTD enterprise. A paper presented at confronting the Challenge of Technology for Development: Experiences from the BRICS (2008), 29-30.

[62] Joyojeet Pal and Meera Lakshmanan. 2012. Assistive technology and the employment of people with vision impairments in India. In Proceedings of the Fifth International Conference on Information and Communication Technologies and Development. ACM, 307-317.

[63] OECD policy brief. 2017. Going Digital: The Future of Work for Women. OECD (2017).

[64] Ghana Pooneh. March 2018. The Future of Work. https: //www.wired.com/brandlab/2018/03/the-future-of-work. (March 2018).

[65] Noopur Raval and Paul Dourish. 2016. Standing out from the crowd: Emotional labor, body labor, and temporal labor in ridesharing. In Proceedings of the 19th ACM Conference on Computer-Supported Cooperative Work \& Social Computing. ACM, 97-107.

[66] Joel Ross, Lilly Irani, M Silberman, Andrew Zaldivar, and Bill Tomlinson. 2010. Who are the crowdworkers?: shifting demographics in mechanical turk. In CHI'10 extended abstracts on Human factors in computing systems. ACM, 2863-2872.

[67] Nithya Sambasivan and Paul M Aoki. 2017. Imagined Connectivities: Synthesized Conceptions of Public Wi-Fi in Urban India. In Proceedings of the 2017 CHI Conference on Human Factors in Computing Systems. ACM, 5917-5928. 
[68] Sreela Sarkar. 2018. Aspirations and Contestations: ICT Training and Subjectivities Among Marginalized Youth. Information Technologies \& International Development 14 (2018), 13.

[69] Karen Schrier. 2006. Using augmented reality games to teach 21 st century skills. In ACM SIGGRAPH 2006 Educators program. ACM, 15.

[70] I Seidman. 2006. A guide for researchers in education and the social sciences. (2006).

[71] Andrew D Selbst, Danah Boyd, Sorelle A Friedler, Suresh Venkatasubramanian, and Janet Vertesi. 2019. Fairness and abstraction in sociotechnical systems. In Proceedings of the Conference on Fairness, Accountability, and Transparency. ACM, 59-68.

[72] Aaron Smith and Janna Anderson. 2014. AI, Robotics, and the Future of Jobs. Pew Research Center 6 (2014).

[73] Will Sutherland and Mohammad Hossein Jarrahi. 2017. The gig economy and information infrastructure: the case of the digital nomad community. Proceedings of the ACM on Human-Computer Interaction 1, CSCW (2017), 97.

[74] Astra Taylor. 2018. The Automation Charade. https://logicmag.io/failure/the-automation-charade/. (August 2018).

[75] Divy Thakkar, Nithya Sambasivan, Purva Kulkarni, Pratap Kalenahalli Sudarshan, and Kentaro Toyama. 2018. The Unexpected Entry and Exodus of Women in Computing and HCI in India. In Proceedings of the 2018 CHI Conference on Human Factors in Computing Systems. ACM, 352.

[76] David R Thomas. 2006. A general inductive approach for analyzing qualitative evaluation data. American journal of evaluation 27, 2 (2006), 237-246.

[77] Kentaro Toyama. 2018. From needs to aspirations in information technology for development. Information Technology for Development 24, 1 (2018), 15-36.

[78] Darrell M. West. 2018. Brookings survey finds worries over AI impact on jobs and personal privacy, concern U.S. will fall behind China. https://www.brookings.edu/blog/techtank/ 2018/05/21/brookings-survey-finds-worries-over-aiimpact-on-jobs-and-personal-privacy-concern-u-swill-fall-behind-china/. (May 2018).

[79] Earnest Wheeler and Tawanna R Dillahunt. 2018. Navigating the job search as a low-resourced job seeker. In Proceedings of the 2018 CHI Conference on Human Factors in Computing Systems. ACM, 48.

[80] Langdon Winner. 1993. Upon opening the black box and finding it empty: Social constructivism and the philosophy of technology. Science, Technology, \& Human Values 18, 3 (1993), 362-378.

[81] Allison Woodruff, Sarah E Fox, Steven Rousso-Schindler, and Jeffrey Warshaw. 2018. A qualitative exploration of perceptions of algorithmic fairness. In Proceedings of the 2018 CHI Conference on Human Factors in Computing Systems. ACM, 656.

[82] Susan P Wyche, Andrea Forte, and Sarita Yardi Schoenebeck. 2013. Hustling online: understanding consolidated facebook use in an informal settlement in Nairobi. In Proceedings of the SIGCHI conference on human factors in computing systems. ACM, 2823-2832.

[83] Baobao Zhang and Allan Dafoe. 2019. Artificial intelligence: American attitudes and trends. Available at SSRN 3312874 (2019).

[84] Kathryn Zyskowski, Meredith Ringel Morris, Jeffrey P Bigham, Mary L Gray, and Shaun K Kane. 2015. Accessible crowdwork?: Understanding the value in and challenge of microtask employment for people with disabilities. In Proceedings of the 18th ACM Conference on Computer Supported Cooperative Work \& Social Computing. ACM, 1682-1693. 